Tohoku J. Exp. Med., 2007, 213, 79-87

\title{
Treatment with Lithium, Alone or in Combination with Olanzapine, Relieves Oxidative Stress but Increases Atherogenic Lipids in Bipolar Disorder
}

\author{
Rezzan Aliyazicioğlu, ${ }^{1}$ Birgül Kural, ${ }^{2}$ Meltem Çolak, ${ }^{2}$ S. Caner Karahan, ${ }^{2}$ \\ Sibel Ayvaz ${ }^{3}$ and Orhan DeĞER ${ }^{2}$ \\ ${ }^{1}$ Vocational School of Health Sciences, Karadeniz Technical University, Trabzon, Turkey \\ ${ }^{2}$ Department of Biochemistry, Faculty of Medicine, Karadeniz Technical University, Trabzon, \\ Turkey \\ ${ }^{3}$ Department of Psychiatry, Faculty of Medicine, Karadeniz Technical University, Trabzon, Turkey
}

\begin{abstract}
AliyazicioĞLu, R., Kural, B., Çolak, M., Karahan, S.C., Ayvaz, S. and DeĞEr, O. Treatment with Lithium, Alone or in Combination with Olanzapine, Relieves Oxidative Stress but Increases Atherogenic Lipids in Bipolar Disorder. Tohoku J. Exp. Med., 2007, 213 (1), 79-87 — The changes in antioxidant-oxidant balance play important roles in the pathopysiology of neuropsychiatric conditions. Bipolar disorder (BD) is a psychiatric condition with recurrent mood disturbances. This study evaluates the effects of treatment with lithium, alone or in combination with antipsychotic olanzapine, on oxidant-antioxidant status and atherogenic character in patients with BD. The blood samples from 15 patients were tested before the treatment (pre-treatment phase) and at the ends of two consecutive treatment periods: period I, treatment with lithium and an antipsychotic drug, olanzapine (first 6 months) and period II, treatment with only lithium (6 months following period I). We measured serum atherogenic lipids (total cholesterol, triglycerides, and LDL-cholesterol), plasma lipid peroxides (thiobarbituric acid-reactive substances), antioxidant enzymes (glutathione peroxidase, superoxide dismutase, and catalase) in neutrophils and lymphocytes, and total antioxidant status in plasma. Compared with pre-treatment phase, the lipid parameters were increased with each treatment; especially, LDL-cholesterol was significantly increased only with lithium treatment. These findings alert to be cautious about use of lithium in patients with atherogenic conditions. Moreover, plasma lipid peroxides were decreased significantly after the combination therapy and further decreased with lithium treatment. Antioxidant enzyme activities in lymphocytes were decreased after both types of treatment. Importantly, plasma total antioxidant status was increased only with lithium treatment. Thus, treatment with lithium alone decreases already up-set oxidant status in BD. In conclusion, the combination therapy with olanzapine is better in terms of atherogenic profile, while lithium alone produces better antioxidant status in patients with BD.

bipolar disorder; lithium; olanzapine; antioxidant parameters; lipids

(C) 2007 Tohoku University Medical Press
\end{abstract}

Received March 19, 2007; revision accepted for publication August 2, 2007.

Correspondence: Rezzan Aliyazıcıoğlu, K.T.U. Vocational School of Health Sciences, 61080, Trabzon, Turkiye.

e-mail: rezzanaoglu@mynet.com 
Bipolar disorder (BD) is the name of common, recurrent, and disabling entities in the etiopathogenesis, in which psychological, social, genetic, biochemical, and other factors are involved (Savaş et al. 2002). Patients with BD experience fluid states of mania, hypomania or what is referred to as a mixed state together with depressive episodes. These clinical states typically alternate with a normal range of mood. Lithium is the most widely used drug in many cases, and the treatment may continue for many years, even life-long. In addition to the effects on treating manic and depressive periods, lithium extents the time between episodes and blocks the formation of new episodes. Olanzapine is a new antipsychotic. Lithium and olanzapine have various and many serious side effects on thyroid hormones, lipid metabolism, electrolyte balance, trace elements, and therefore membrane potential and transport, enzyme activities and oxidantantioxidant balance (Aliyazıcıoğlu et al. 2003; McKee et al. 2005). Olanzapine also displays potent activity on dopaminergic, serotoninergic, muscarinic, histaminergic, and adrenergic receptors.

Reactive oxygen species (ROS) are continuously produced by the body's metabolism in many different ways, such as activation of phagocytes and the general immune system, lipid peroxidation, the electron transport system in mitochondria, ischemia, and trauma (Halliwell and Gutteridge 2000). Enzymatic and nonenzymatic antioxidant systems protect against ROS, which cause lipid, protein, and DNA oxidation, and, thus, are involved in etiopathogenesis of many diseases such as cancer and neurological and psychiatric disorders including BD (Halliwell and Aruoma 1991; Mahadik and Mukherjee 1996; Casarino and Bennett 1999; Cooke et al. 2003). Bilici et al. (2001) found higher levels of glutathione peroxidase (GSH-Px) and superoxide dismutase (SOD) in erythrocytes of patients with major depressive disorder (melancholia type) than those of healthy control subjects.

In this study, we evaluated the effects of lithium with or without a antipsychotic drug olanzapine on the oxidant status as lipid peroxidation and antioxidant status as antioxidant enzymes of lymphocytes and neutrophils in patients with BD. In addition, plasma lipid peroxidation level as thiobarbituric acid-reactive substances (TBARS), and total antioxidant status (TAS) were determined. Thus, a comprehensive investigation of oxidantantioxidant status of neutrophils, lymphocytes, and plasma together is expected to contribute to the literature.

\section{Methods}

\section{Chemicals}

All the reagents used were analytical grade. Xanthine oxidase and xanthine were purchased from Merck (Darmstadt, Germany); 1,1,3,3-tetraethoxypropane, thiobarbituric acid (TBA), phosphotungstic acid, EDTA-Na ${ }_{2}$, nicotinamide adenine dinucleotide phosphate (NADP, oxidized form), $\beta$-nicotinamide adenine dinucleotide phosphate ( $\beta$-NADPH, reduced form), catalase (from bovine liver), SOD (from bovine liver), GR (from bakers yeast), reduced glutathione (GSH), oxidized glutathione (GSSG), albumin (from bovine serum), 3cyclohexylamino (2-hydroxy-1-propane sulfonic acid) (CAPS), and 2-(4-iodophenyl)-3-(4-nitrophenol)-5-phenyltetrazoliumchloride (INT) were purchased from Sigma (Steinheim, Germany; St. Louis, MO, USA); Percoll was purchased from Pharmacia (Uppsala, Sweden). Water used was double-distilled and deionized. All reagents except the phosphate buffers were prepared daily and stored at $4^{\circ} \mathrm{C}$. The reagents were equilibrated at room temperature for $0.5 \mathrm{hrs}$ before use when the analysis was initiated or reagent containers were refilled.

\section{Human subjects}

The study group consisted of 15 patients ( 7 male and 8 female, mean age $37 \pm 8.2$ [s.D.]) who had applied to the Department of Psychiatry, College of Medicine at Karadeniz Technical University between May 2002 and August 2003 and diagnosed with BD $(n=15)$ according to the Diagnostic and Statistical Manual of Mental Disorders IV (American Psychiatric Association 1994). BD has generally been subdivided into bipolar I, bipolar IIrapid cycling variant, and cyclothymia. Major distinction of bipolar I is the presence of mania in addition to depression, which is seen all three types. All the subjects of the current study fall within bipolar I type.

The blood samples from 15 BD patients were collected before the treatment (pretreatment phase) and after the treatments within two periods. In the period I (first 6 
months), patients were administrated lithium carbonate and antipsychotic drug olanzapine. Blood lithium levels were restricted in the $0.8-1.2 \mathrm{mg} / \mathrm{dl}$ range. Olanzapine was used during the acute manic episodes at $20 \mathrm{mg}$ per day. Approximately one month later, the elevated mood was euthymic. After that, olanzapine dose was decreased to $10 \mathrm{mg} /$ day for 2 months, to $5 \mathrm{mg}$ /day for 3 months. In the period II (7-12 months), the patients were only administrated lithium carbonate. Blood lithium level of patients in the period II following the treatment was restricted in the $0.6-1.2 \mathrm{mg} / \mathrm{dl}$ range.

Physical examination and anamnesis were performed for each of the patients. Liver and kidney function tests were evaluated. Subjects having normal results were admitted to the study. None of the subjects included in the study had alcohol and substance abuse or dependence, tardive dyskinesia related to neuroleptics, presence of severe organic conditions, any antioxidant agent (i.e., $\mathrm{E}$ and $\mathrm{C}$ vitamins) use, epilepsy and severe neurological disorder, any infectious disease, or excessive obesity.

All experiments were performed in compliance with institutional guidelines. Informed consent was obtained from all the subjects.

\section{Blood sampling}

After an overnight fasting period, blood samples from the subjects were drawn into the tubes containing anticoagulant $\mathrm{K}_{3}$ EDTA and the vacutainer tubes without anticoagulant (containing separatory gel). The blood samples containing anticoagulant were centrifuged at $2,000 \times \mathrm{g}$ for $10 \mathrm{~min}$ at $4^{\circ} \mathrm{C}$ to separate plasma, neutrophils, and lymphocytes. Plasma aliquots were stored at $-80^{\circ} \mathrm{C}$ in deep freezer until the analyses of TAS and TBARS. Neutrophils and lymphocytes isolation was accomplished by the modified method of Sharpe (1988). Neutrophils and lymphocytes were isolated by a two-step discontinuous Percoll gradient centrifugation (1.110 $\mathrm{g} / \mathrm{cm}^{3}$ and $1.077 \mathrm{~g} / \mathrm{cm}^{3}$, at $700 \times \mathrm{g}$ for $30 \mathrm{~min}$ at room temperature). The upper layer containing lymphocytes and monocytes was washed with phosphate-buffered saline (PBS, pH 7.4) and lymphocytes were isolated. The lower layer containing the neutrophils band was washed once with PBS, the cell suspensions were suspended for $10 \mathrm{sec}$ in chilled $0.2 \% \mathrm{NaCl}$ solution to lyse contaminating erythrocytes, and the residue was diluted with $1.6 \% \mathrm{NaCl}$ solution. The final cell suspension was resuspended in the same buffer and cell concentration was adjusted to $1 \times 10^{6}$ cells $/ \mathrm{ml}$. Purified suspensions contained 90-98\% lymphocytes and 90-95\% neutrophils based on measurements by automatic blood counter (Coulter Corp., STKS).

Protein content in the neutrophils and lymphocytes were performed by the method of Lowry et al. (1951).

The blood samples without anticoagulant were centrifuged at 2,000 $\times \mathrm{g}$ for $10 \mathrm{~min}$ after coagulation and serum samples were separated. Total cholesterol (TC), tryglycerides (TG), HDL-cholesterol, LDL-cholesterol, Apo A1, Apo B, leukocytes, neutrophils, lymphocytes, erythrocyte sedimentation rate (ESR), C-reactive protein (CRP) were analyzed immediately.

Determinations of lipids, lipoproteins, and acute phase reactant levels

The levels of serum TC and TG were determined by enzymatic methods using Roche Diagnostics Modular DP analytic system (Germany) with original reagents. HDL-cholesterol by the cholesterol oxidase enzymatic method in the supernatant was obtained after precipitation with phosphotungustic acid-magnesium chloride. LDL-cholesterol was calculated by using Friedewald Formula (Friedewald et al. 1972). Apo A1, apo B and CRP were determined by immunonephelometry (Dade Behring, BN II). ESR was determined by classical Westergren method and cells (lymphocytes, neutrophils, leukocytes) counting by an automated blood counter (STKS, Coulter).

\section{Determination of oxidant-antioxidant status in plasma}

Total antioxidant status (TAS) assay. A kit manufactured by Randox Laboratories (Cat. No. NX 2332) enables the TAS to be measured in human plasma. The Randox kit utilizes ABTS (2,2'-azino-di-[3-ethylbenzthiazoline sulphonate]) which is converted to its cation form when incubated in the presence of a peroxidase and hydrogen peroxide $\left(\mathrm{H}_{2} \mathrm{O}_{2}\right)$. This cation has a fairly stable blue - green colour which can be measured at $600 \mathrm{~nm}$. Antioxidants present in the sample suppress the colour formation in the proportion of their concentrations. Exactly $4 \mu 1$ of platelet-poorplasma (PPP) or a standard of known concentration is incubated with $200 \mu$ of a reagent containing methmyoglobin and $\mathrm{ABTS}$ at $37^{\circ} \mathrm{C}$ for $15 \mathrm{sec}$. After addition of $40 \mu \mathrm{l} \mathrm{H}_{2} \mathrm{O}_{2}$, the reaction is followed for $3 \mathrm{~min}$. The results are expressed as nmol/l of PPP.

Lipid peroxidation assay. Plasma lipid peroxide levels were measured by the method of Yagi (1994). 
Lipids and proteins were precipitated by using a phosphotungstic acid-sulphuric acid system (10\%, and 0.084 $\mathrm{N}$, respectively) from other TBA-reactive substances such as glucose and water-soluble aldehydes in the plasma. After the TBA reaction, the product concentration was determined by the absorption at $532 \mathrm{~nm}$. TBARS standards were prepared with 1,1,3,3- tetraethoxypropane. The results are expressed as $\mathrm{nmol} / \mathrm{ml}$.

Determination of oxidant-antioxidant status in neutrophils and lymphocytes

Lipid peroxidation assay. Lipid peroxides in neutrophil and lymphocyte suspensions were determined by the method of Uchiama and Mihara (1978). Three ml of $1 \%$ phosphoric acid and $1 \mathrm{ml}$ of $0.6 \%$ TBA solution were added to $0.5 \mathrm{ml}$ sample in a tube. The mixture was heated in boiling water for $45 \mathrm{~min}$. After cooling, the colored product was extracted into $4 \mathrm{ml} n$-butanol and the absorbance was measured at $532 \mathrm{~nm}$, spectrophotometrically. The results are expressed as $\mathrm{nmol} / \mathrm{g}$ protein.

Superoxide dismutase (SOD) activity assay. Determination of total SOD activity was performed by the method of Ransod (Randox Labs) based on the method developed by coupling an $\mathrm{O}_{2}^{-}$generator with an $\mathrm{O}_{2}{ }^{-}$ detector (McCord and Fridovich 1969). Xanthine and xanthine oxidase were used to generate $\mathrm{O}_{2}^{-}$, and INT, which reacts with $\mathrm{O}_{2}{ }^{-}$to form a red formazan dye, was used for detection. SOD inhibits the formation of the formazan dye, and the activity was measured as percent inhibition compared with a calibration curve with purified SOD. The final concentrations of the reagents used in the assay were as follows; $0.05 \mathrm{mmol} / 1$ xanthine and $0.025 \mathrm{mmol} / \mathrm{l} \mathrm{INT}$ in the main reagent and $80 \mathrm{U} / 1 \mathrm{xan}-$ thine oxidase in the starting reagent. The sample (protein concentration 320-360 $\mu \mathrm{g} / \mathrm{ml}$ ) was first diluted two fold in potassium phosphate buffer (10 mmol/l; $\mathrm{pH} \mathrm{7.0)}$ and 5 $\mu 1$ (plus $20 \mu \mathrm{l}$ of $\mathrm{H}_{2} \mathrm{O}$ ) were added concomitantly with the main reagent $(170 \mu \mathrm{l})$. Absorbance was monitored at $505 \mathrm{~nm}$ for $150 \mathrm{sec}$ after the addition of xanthine oxidase ( $25 \mu 1$ plus $10 \mu 1$ of $\mathrm{H}_{2} \mathrm{O}$ ) as starting reagent. The final reaction volume was $230 \mu \mathrm{l}$. One unit is the amount of superoxide dismutase that inhibits the rate of the formazan dye formation by $50 \%$. This assay was linear from 30 to $60 \%$ inhibition. The results were expressed as U/g protein.

GSH-Px activity assay. The activity of GSH-Px was determined by a modified method of Beutler (1971). The reaction mixture contained $100 \mathrm{mmol} / \mathrm{l}$ potassium phosphate buffer (pH 7.0), 1 mmol/1 GSH, 2 mmol/l EDTA, $1,000 \mathrm{U} / \mathrm{l} \mathrm{GR}, 4 \mathrm{mmol} / 1 \mathrm{NaN}_{3}, 0.2 \mathrm{mmol} / \mathrm{l} \mathrm{NADPH}$, and $0.1 \mathrm{mmol} / 1 \mathrm{H}_{2} \mathrm{O}_{2}$ and $50 \mu 1$ undiluted suspension of neutrophils. Before the addition of $\mathrm{H}_{2} \mathrm{O}_{2}$, the reaction mixture was incubated for $10 \mathrm{~min}$ at $37^{\circ} \mathrm{C}$. After the addition of $\mathrm{H}_{2} \mathrm{O}_{2}$, the decrease in reduced NADPH was followed at $340 \mathrm{~nm}$. The results were expressed as $\mathrm{U} / \mathrm{g}$ protein.

Glutathione reductase (GR) activity assay. GR activity was measured by following the decrease in absorbance due to the oxidation of NADPH (Goldberg and Spooner 1987). The reaction mixture contained 100 $\mathrm{mmol} / \mathrm{l}$ potassium phosphate buffer $(\mathrm{pH} 7.2), 0.5 \mathrm{mmol} / \mathrm{l}$ EDTA- $\mathrm{Na}_{2} .2 \mathrm{H}_{2} \mathrm{O}, 2.2 \mathrm{mmol} / 1 \mathrm{GSSG}$, and $0.17 \mathrm{mmol} / \mathrm{l}$ $\mathrm{NADPH}$, and $10 \mu 1$ sample. Before the addition of NADPH, contents of the cuvette were mixed thoroughly and left for $5 \mathrm{~min}$. Oxidation of NADPH was measured at $340 \mathrm{~nm}$. Results are expressed as U/g protein.

Catalase (CAT) activity assay. CAT activity was determined by the method described by Aebi (1987) by using a UV/visible spectrophotometer (LKB, ultraspec $\mathrm{K})$. CAT activity was determined by following the reduction rate of $\mathrm{H}_{2} \mathrm{O}_{2}$ in the presence of catalase containing neutrophil and lymphocyte suspensions from 12 $\mathrm{sec}$ to $30 \mathrm{sec}$, using a spectrophotometer at $240 \mathrm{~nm}$. The activity was expressed as follows:

$$
k=\frac{2.3}{18} x \log \frac{A 1}{A 2}
$$

where $k$ is the first order rate constant of the reaction, $A_{1}$ is the $\mathrm{OD}(240 \mathrm{~nm})$ at $12 \mathrm{sec}$ in the assay mixture consisting of $10 \mathrm{mmol} / 1 \mathrm{H}_{2} \mathrm{O}_{2}$ prepared in $3 \mathrm{ml}$ of $50 \mathrm{mmol} / \mathrm{l}$ phosphate buffer (pH 7.0) and $50 \mu 1$ sample, $A_{2}$ is the OD $(240 \mathrm{~nm})$ at $30 \mathrm{sec}$ in the same mixture. The results are expressed as $\mathrm{k} / \mathrm{g}$ protein.

\section{Statistical analysis}

Data are expressed as the mean $(\bar{X}) \pm$ S.D. Normal distribution of variables in the study groups was assessed by the Kolmogorov Smirnov test. The parameters not within normal distribution were analyzed by the Friedman test (Wilcoxon test with Bonferroni correction as post hoc). The parameters within normal distribution were analyzed by the analysis of variance in repeated measurements (paired $t$-test as post hoc). Differences at $p<0.05$ level were considered to be statistically significant. 


\section{RESUlTS}

The levels of lipid and lipoprotein parameters, acute phase reactant, blood count parameters in patients with BD are shown in Table 1. TC, TG, LDL-cholesterol, and apo B levels were increased $(F=28.179, p=0.001 ; F=0.660$, $p=0.024 ; F=0.015, p=0.034$, and $F=67.665$, $p=0.001$, respectively) with treatment, but the increase was more pronounced in period II, with only lithium treatment. HDL-cholesterol and apo A1 did not change $(F=1.012, p=0.376)$. Neutrophils decreased $(F=5.992, p=0.007)$, but lymphocytes increased $(F=12.207, p=0.001)$ in both periods. CRP decreased with combined treatment, but then increased with only lithium treatment $(F=10.020, p=0.004)$. CRP level after the treatment in both periods was lower than pretreatment phase. Treatments did not affect ESR levels $(F=0.008, p=0.975)$.

The levels of plasma, neutrophil, and lymphocyte oxidant-antioxidant status parameters are shown in Table 2. Plasma TBARS levels were decreased with treatment in both periods I and II $(F=3.410, p=0.001)$. TBARS levels decreased in neutrophils and lymphocytes $(F=2.349, p=$ $0.114 ; F=2.313, p=0.118$, respectively), but the change was not statistically significant. GSH-Px activity was decreased $(F=2.32, p=0.001)$ with treatment in neutrophils. In lymphocytes GSH-Px activity was decreased with treatment ( $F=$ $14.408, p=0.001)$. SOD activity was decreased in period I, but increased in period II $(F=76.079$, $p=0.001)$. CAT and GR activities were increased in period I, but decreased in period II $(F=3.939$, $p=0.031 ; F=3.789, p=0.050$, respectively). Other antioxidant enzymes did not show any significant change with each treatment.

TABLE 1. Serum lipids, acute phase reactants, and blood count parameters in patients with BD $(n=15)$.

\begin{tabular}{|c|c|c|c|c|c|c|}
\hline & \multirow[b]{2}{*}{ Normal ranges ${ }^{\mathrm{a}}$} & \multirow[b]{2}{*}{$\begin{array}{c}\text { Pre-treatment } \\
\bar{X} \pm \text { S.D. }\end{array}$} & \multicolumn{2}{|c|}{ After treatment } & \multirow[b]{2}{*}{$F_{\text {ratio }}$} & \multirow[b]{2}{*}{$p$ value } \\
\hline & & & $\begin{array}{l}\text { Period I } \\
\bar{X} \pm \text { S.D. }\end{array}$ & $\begin{array}{l}\text { Period II } \\
\bar{X} \pm \text { S.D. }\end{array}$ & & \\
\hline Total cholesterol (mg/dl) & $150-200$ & $169 \pm 34$ & $176 \pm 50^{\mathrm{b}}$ & $201 \pm 46^{\mathrm{b}, \mathrm{c}}$ & 28.179 & 0.001 \\
\hline Triglycerides (mg/dl) & $50-150$ & $137 \pm 98$ & $157 \pm 48^{\mathrm{b}}$ & $167 \pm 44^{\mathrm{b}, \mathrm{c}}$ & 0.660 & 0.024 \\
\hline HDL-cholesterol (mg/dl) & $45-65$ & $49 \pm 13$ & $50 \pm 8$ & $48 \pm 8$ & 1.035 & 0.368 \\
\hline LDL-cholesterol (mg/dl) & $65-175$ & $97 \pm 52$ & $98 \pm 26$ & $127 \pm 24^{\mathrm{b}, \mathrm{c}}$ & 0.015 & 0.034 \\
\hline Apo A1 (mg/dl) & $115-210$ & $133 \pm 30$ & $138 \pm 17$ & $138 \pm 15$ & 1.012 & 0.376 \\
\hline Apo B (mg/dl) & $55-135$ & $82 \pm 26$ & $88 \pm 33^{b}$ & $103 \pm 28^{\mathrm{b}, \mathrm{c}}$ & 67.665 & 0.001 \\
\hline Leukocytes $\left(10^{3} / \mu 1\right)$ & $4.80-10.80$ & $7.14 \pm 1.74$ & $7.85 \pm 2.38$ & $6.98 \pm 1.49$ & 2.659 & 0.088 \\
\hline Neutrophils (\%) & $43-65$ & $65 \pm 9$ & $62 \pm 12^{b}$ & $56 \pm 7^{\mathrm{b}, \mathrm{c}}$ & 5.992 & 0.007 \\
\hline Lymphocytes (\%) & $20.5-45.5$ & $25 \pm 7$ & $28 \pm 10^{\mathrm{b}}$ & $33 \pm 7^{b, c}$ & 12.207 & 0.001 \\
\hline $\operatorname{ESR}(\mathrm{mm} / \mathrm{r})$ & $0-20$ & $9 \pm 4$ & $8 \pm 6$ & $8 \pm 5$ & 0.008 & 0.975 \\
\hline $\mathrm{CRP}(\mathrm{mg} / \mathrm{dl})$ & $<0.5$ & $0.46 \pm 0.35$ & $0.37 \pm 0.15^{\mathrm{b}}$ & $0.41 \pm 0.16^{\mathrm{b}, \mathrm{c}}$ & 10.020 & 0.004 \\
\hline
\end{tabular}

Period I: Measurements were made at the end of the first six months during which combined olanzapine and lithium therapy is applied in patients with BD.

Period II: Measurements were made at the end of the second six months during which only lithium therapy is applied in patients with BD.

$n$, number of patients; $\bar{X}$, mean; s.D., standard deviation; p, significant level; a, normal values used as reference; $\mathrm{b}$, values are significantly different from those of pre-treatment phase $(p<0.05)$; $\mathrm{c}$, values are significantly different from those of period I $(p<0.05)$; CRP, C-reactive protein; ESR, erythrocyte sedimentation rate. 
TABLE 2. Antioxidant enzymes activities, and the levels of lipid peroxidation product and total antioxidant status in patients with $\mathrm{BD}(n=15)$.

\begin{tabular}{|c|c|c|c|c|c|}
\hline & \multirow{2}{*}{$\begin{array}{c}\text { Pre-treatment } \\
\bar{X} \pm \text { S.D. }\end{array}$} & \multicolumn{2}{|c|}{ After treatment } & \multirow[b]{2}{*}{$F_{\text {ratio }}$} & \multirow[b]{2}{*}{$p$ value } \\
\hline & & $\begin{array}{l}\text { Period I } \\
\bar{X} \pm \text { S.D. }\end{array}$ & $\begin{array}{l}\text { Period II } \\
\bar{X} \pm \text { S.D. }\end{array}$ & & \\
\hline \multicolumn{6}{|l|}{ NEUTROPHILS } \\
\hline TBARS (nmol/g protein) & $65 \pm 31$ & $48 \pm 19$ & $45 \pm 26$ & 2.349 & 0.114 \\
\hline GSH-Px (U/g protein) & $47 \pm 18$ & $37 \pm 13^{\mathrm{a}}$ & $29 \pm 7.4^{\mathrm{a}}$ & 2.320 & 0.001 \\
\hline GR (U/g protein) & $24 \pm 4.4$ & $26 \pm 6.3$ & $25 \pm 6.7$ & 0.536 & 0.591 \\
\hline SOD (U/g protein) & $26 \pm 3.8$ & $24 \pm 1.6$ & $26 \pm 3.5$ & 1.519 & 0.237 \\
\hline CAT (k/g protein) & $82 \pm 55$ & $56 \pm 29$ & $70 \pm 21$ & 1.854 & 0.175 \\
\hline \multicolumn{6}{|l|}{ LYMPHOCYTES } \\
\hline TBARS (nmol/g protein) & $48 \pm 15$ & $42 \pm 6.5$ & $41 \pm 6.6$ & 2.313 & 0.118 \\
\hline GSH-Px (U/g protein) & $70 \pm 13$ & $47 \pm 15^{\mathrm{a}}$ & $46 \pm 14^{\mathrm{a}}$ & 14.408 & 0.001 \\
\hline GR (U/g protein) & $29 \pm 20$ & $41 \pm 16^{\mathrm{a}}$ & $31 \pm 6.5^{\mathrm{a}}$ & 3.789 & 0.050 \\
\hline SOD (U/g protein) & $190 \pm 15$ & $142 \pm 12^{\mathrm{a}}$ & $162 \pm 12^{\mathrm{a}}$ & 76.079 & 0.001 \\
\hline CAT (k/g protein) & $38 \pm 23$ & $46 \pm 24^{\mathrm{a}}$ & $31 \pm 8.7^{\mathrm{b}}$ & 3.939 & 0.031 \\
\hline \multicolumn{6}{|l|}{ PLASMA } \\
\hline TBARS (nmol/ml) & $5.0 \pm 1.1$ & $3.5 \pm 0.84^{\mathrm{a}}$ & $2.8 \pm 0.76^{\mathrm{a}, \mathrm{b}}$ & 3.410 & 0.001 \\
\hline TAS (nmol/l) & $1.08 \pm 0.17$ & $0.93 \pm 0.21$ & $1.26 \pm 0.25^{\mathrm{a}, \mathrm{b}}$ & 2.231 & 0.001 \\
\hline
\end{tabular}

Period I: Measurements were made at the end of the first six months during which combined olanzapine and lithium therapy is applied in patients with BD.

Period II: Measurements were made at the end of the second six months during which only lithium therapy is applied in patients with BD.

$n$, number of patients; $\bar{X}$, mean; s.D., standard deviation; $p$, significant level; a, values are significantly different from those of pre-treatment phase $(p<0.05)$; $\mathrm{b}$, values are significantly different from those of period I ( $p<0.05)$; TBARS, thiobarbituric acid-reactive substances; GSH-Px, glutathione peroxidase; GR, glutathione reductase; SOD, superoxide dismutase; CAT, catalase; TAS, total antioxidant status.

\section{Discussion}

While the exact cause of BD has not been elucidated, there are likely to be multiple contributors to the pathoetiology of the disorder. A number of studies have implicated several areas of the brain and have focused attention towards abnormalities in the intra-cellular processes of brain function, such as those involving cell receptors and neurotransmitter effects. The brain is much more vulnerable to reactive oxygen species than other tissues, since it utilizes $20 \%$ of the oxygen consumed by the body, although it comprises only $2 \%$ of the body weight (Clarke and Sokoloff 1999). In addition, the central nervous system has high iron content and contains an abundance of polyunsaturated fatty acids, the target of lipid peroxidation (Gerlach et al. 1994; Dringen et al. 2000). Furthermore, the brain shows a rather low concentration of antioxidant enzymes such as catalase, in contrast to peripheral organs like kidney or liver (Cooper 1997). Catecholamines are probably associated with the production of free radicals and conditions causing increased catecholamine metabolism may increase the free radical burden (Graham 1978). In addition, brain damage may cause increased free radical production.

Blood cells, such as eosinophils, platelets, neutrophils, monocytes, and macrophages, synthesize antioxidant enzymes. Among these 
cells, neutrophils constitute an important proportion and are also major participants in a number of pathological conditions that suggest involvement of antioxidant enzymes. There is an increasing understanding toward neutrophils, antioxidant enzymes and their regulatory role in neutrophil function. Neutrophils have a short half-life and high tendency to undergo apoptosis. One feature that may influence these characteristics is the antioxidant/oxidant balance of these cells. Neutrophils play a central role in inflammatory and infectious diseases. They generate superoxide by the respiratory burst through the activation of NADPH oxidase. Neutrophils have a higher oxidant production than other inflammatory cells. Kinnula et al. (2002) found that neutrophils have high catalase activity but lower level of glutathione-dependent antioxidant enzymes. The differences in antioxidant profiles in neutrophils and monocytes may have important effects on the life span of human neutrophils, in both healthy and diseased tissues.

The present study revealed that antipsychotic olanzapine and lithium treatment affect the oxidant-antioxidant status in patients with BD. In the period II, plasma TBARS levels were found to be significantly lower than those in the period I and in the pre-treatment phase. Increased TBARS levels without treatment of the disorder have been reported to disable cellular membrane functions by stimulating phospholipase $\mathrm{A}_{2}$ and thus release interleukins by stimulating the immune system (Sierra and Murphy 1992).

No investigation has evaluated alterations in plasma TAS levels during lithium therapy in patients with BD. Yao et al. (1998) found significantly lower levels of TAS in plasma of patients with schizophrenia than in normal controls. We found that plasma TAS levels in pre-treatment phase were significantly lower than those in period II. In addition, when the period I and the period II were compared, TAS values were observed to increase significantly in period II. Increased level of plasma TAS levels with lithium therapy may have pathophysiological significance in BD. Pathophysiological implications of decreased TAS in the period before the treatment will ultimately require the demonstration that oxidative stress indeed occurs in the brain. Since TAS is a measure of capacity to scavenge free radicals, the consequences of decreased TAS in pre-treatment phase in plasma may lead to an increased free radical mediated cellular insult, such as lipid peroxidation, in the brain.

We measured neutrophil and lymphocyte antioxidant enzyme activities including SOD, GSH-Px, GR, and CAT in BD. In the period II, neutrophil and lymphocyte GSH-Px levels were found significantly lower than those of pre-treatment phase and period I.

The imbalance between the rate of free radical production and the effect of protective antioxidatiants leads to oxidative stress, which results in various types of oxidative damage. SOD is an enzyme extensively used as a biochemical indicator of pathological states associated with oxidative stress. SOD catalyzes dismutation of the superoxide anion $\left(\mathrm{O}_{2}^{-}\right)$into $\mathrm{H}_{2} \mathrm{O}_{2} \cdot \mathrm{H}_{2} \mathrm{O}_{2}$ is one of the most active oxygen species (Chance et al. 1979). GSH-Px is regarded to be critical for maintaining low levels of cellular $\mathrm{H}_{2} \mathrm{O}_{2}$ and lipid peroxides. The $\mathrm{H}_{2} \mathrm{O}_{2}$ needs GSH-Px and CAT to be further converted to the respective alcohols and water. Abdalla et al. (1986) reported that manic-depressive patients treated with lithium alone or with a combination of lithium and antipsychotics showed increased SOD activities that were approximately $40 \%$ higher than those of normal subjects. They reported normal activities of GSH-Px in the blood. Üstdal et al. (2004) reported that erythrocyte SOD level was low, and it increased after lithium treatment. Although CAT activity increased in bipolar affective patients, no effect of lithium on CAT activity was observed. In a study reported by Kuloğlu et al. (2002), SOD activity levels in bipolar patients were found significantly higher than controls, whereas there were no significant changes in GSH-Px activity levels in the bipolar patients and controls group. In our study it was found that lymphocyte SOD, GSH-Px, and CAT levels in the period II were significantly lower than those of pre-treatment phase. In addition, CAT activity decreased in the period II significantly when com- 
pared with the period I. The decreased activity of lymphocyte SOD in patients who took lithium treatment may be functionally coupled to coincident decrease in GSH-Px activity in this cell, given that $\mathrm{H}_{2} \mathrm{O}_{2}$ is both a product of the former and a substrate of the latter enzyme. Parikh et al. (2004) reported that antipsychotics including olanzapine increased the oxidative cellular injury in rats.

The antipsychotic and lithium treatment was observed to lead to an increase in the atherogenic lipids in patients with BD. Lithium treatment has been shown to decrease liver TG content, but increase phospholipids (Ani et al. 2005). Lithium was also reported to inhibit lipoprotein lipase activity (Ani et al. 2005). This inhibitory effect is potentiated in the presence of citrate. Fat cell lipolysis is also inhibited by lithium, which is not reversed by alpha, and beta-receptor blockers indicating that lithium may exert its effect beyond these receptors. Lithium causes changes in the metabolism of lipoproteins. According to the findings of Ani et al. (2005), that lithium decreases HDL and increases LDL concentrations should be considered seriously, especially in patients using this drug for a long period. Huang and Chen (2005) found that responders had significantly increased TC, TG, and VLDL levels and decreased ratio of LDL/HDL after 3 weeks of antipsychotic drug therapy. Cholesterol is an integral component of the central nervous system. It is a major component of cell membranes and is essential for the proper functioning of neurotransmission. In addition, cholesterol function is an important aspect of second messenger systems in the brain. These systems have been associated with the mechanism of action of lithium and may be implicated in the etiology or pathogenesis of mood disorders (Ghaemi et al. 2000). High levels of cholesterol activate thrombocytes and cause the release of substances that activates phospholipase $\mathrm{A}_{2}$. Accumulated arachidonic acid is metabolized to leukotriene by lipoxygenase pathway and thromboxane, prostaglandin and malondialdehyde by cycloxygenase pathway. During this metabolism, oxygen radicals may be produced (Vanizor Kural et al. 2003). Recent data from several reports (Buckman et al. 1987; Cengiz et al. 2000) and our results indicate that free radicals play an important role in the pathogenesis of BD.

In conclusion, lithium and antipsychotic olanzapine treatment might be considered to cause atherosclerotic events because of increasing atherogenic lipids. However, such therapy is also protective against oxidative stress as evident from increased antioxidant status. Therefore, further studies should be performed to clarify the relationship among atherogenic lipids, lipid peroxidation, and antioxidant enzymes in BD.

\section{References}

Abdalla, D.S., Monteiro, H.P., Oliveria, J.A. \& Bechara, E.J. (1986) Activities of superoxide dismutase and glutathione peroxidase in schizophrenic and manic-depressive patients. Clin. Chem., 32, 805-807.

Aebi, H.E. (1987) Catalase. In: Methods of Enzymatic Analysis, Vol. 3, edited by H.U. Bergmeyer, Weinheim, VCH Verlag, pp. 273-278.

Aliyazıcıoğlu, R., Karahan, C., Değer, O. \& Kural, B. (2003) Biological and medical effects of lithium. Ibni Sina Medical J., 8, 1-14. (in Turkish)

American Psychiatric Association (1994) Diagnostic and Statistical Manual of Mental Disorders, 4th ed., American Psychiatric Press, Washington, DC, pp. 288-289.

Ani, M., Moshtaghie, A.A. \& Akbarzadeh, S. (2005) Changes in Biochemical Parameters Related to Lipid Metabolism Following Lithium Treatment in Rat. Iran. Biomed. J., 9, 27-32.

Beutler, E. (1971) Red Cell Metabolism. A Manual of Biochemical Methods, New York: Grune \& Stratton, pp. 64-68.

Bilici, M., Efe, H., Koroglu, M.A., Uydu, H.A., Bekaroglu, M. \& Deger, O. (2001) Antioxidative enzyme activities and lipid peroxidation in major depression: alterations by antidepressant treatment. J. Affect. Disord., 64, 43-51.

Buckman, T.D., Kling, A.S., Eiduson, S., Sutphin, M.S. \& Steinberg, A. (1987) Glutathione peroxidase and CT scan abnormalities in schizophrenia. Biol. Psychiatry, 22, 1349-1356.

Casarino, D.S. \& Bennett, J.P., Jr. (1999) An evaluation of the role of mitochondria in neurodegenerative diseases: mitochondrial mutations and oxidative pathology, protective nuclear responses, and cell death in neurodegeneration. Brain Res. Rev., 29, 1-25.

Cengiz, M., Yüksel, A. \& Seven, M. (2000) The effects of carbamazepine and valproic acid on the erythrocyte glutathione, glutathione peroxidase, superoxide dismutase and serum lipid peroxidation in epileptic children. Pharmacol. Res., 41, 423-425.

Chance, B., Sies, H. \& Boveris, A. (1979) Hydroperoxide metabolism in mammalian organs. Physiol. Rev., 59, 527-605.

Clarke, D.D. \& Sokoloff, L. (1999) Circulation and energy metabolism of the brain. In: Basic neurochemistry: Molecular, cellular, and medical aspects, edited by G.J. Siegel, B.W. Agranoff, R.W. Albers, S.K. Fisher \& M.D. Uhler, Lippincott-Raven, Philadelphia, PA, pp. 637-669. 
Cooke, M.S., Evans, M.D., Dizdaroğlu, M. \& Lunec, J. (2003) Oxidative DNA damage: mechanisms, mutation and disease. FASEB J., 17, 1195-1214.

Cooper, A.J.L. (1997) Glutathione in the brain: disorders of glutathione metabolism, In: The molecular and genetic basis of neurological disease, edited by R.N. Rosenberg, S.B. Prusiner, S. DiMauro, R.L. Barchi \& L.M. Kunk, Butterworth-Heinemann, Boston, MA, pp. 1195-1230.

Dringen, R., Gutterer, J.M. \& Hirrlinger, J. (2000) Glutathione metabolism in the brain. Eur. J. Biochem., 267, 4912-4916.

Friedewald, W.T., Levy, R.I. \& Fredricson, D.S. (1972) Estimation of the concentration of low-density lipoprotein cholesterol in plasma, without use of the preparative ultracentrifuge. Clin. Chem., 18, 499-502.

Gerlach, M., Ben-Sachar, D., Riederer, P. \& Youdim, M.B.H. (1994) Altered brain metabolism of iron as a cause of neurodegenerative diseases? J. Neurochem., 63, 793-807.

Ghaemi, S.N., Shields, G.S., Hegarty, J.D. \& Goodwin, F.K. (2000) Cholesterol levels in mood disorders: high or low? Bipolar Disord., 2, 60-64.

Goldberg, D.M. \& Spooner, R.J. (1987) Glutathione reductase, In: Methods of Enzymatic Analysis, Vol. 3, edited by H.U. Bergmeyer, Weinheim, VCH Verlag, pp. 258-264.

Graham, D.G. (1978) Oxidative pathways for catecholomines in the genesis of neuromelanin and cytotoxic quinones. Mol. Pharmacol., 14, 633-643.

Halliwell, B. \& Aruoma, O.I. (1991) DNA damage by oxygenderived species. Its mechanism and measurement in mammalian systems. FEBS Lett., 281, 9-19.

Halliwell, B. \& Gutteridge, J.M.C. (2000) Free Radicals in Biology and Medicine, 3th ed., Oxford University Press, Oxford, UK, pp. 617-624.

Huang, T.L. \& Chen, J.F. (2005) Serum lipid profiles and schizophrenia: Effects of conventional or atypical antipsychotic drugs in Taiwan. Schizophr. Res., 80, 55-59.

Kinnula, V.L., Soini, Y., Kvist-Makela, K., Savolainen, E.R. \& Koistinen, P. (2002) Antioxidant Defense Mechanisms in Human Neutrophils. Antioxid. Redox Signal., 4, 27-34.

Kuloğlu, M., Ustundag, B., Atmaca, M., Canatan, H., Tezcan, A.E. \& Cinkilinc, N. (2002) Lipid peroxidation and antioxidant enzyme levels in patients with schizophrenia and bipolar disorder. Cell Biochem. Funct., 20, 171-175.

Lowry, O.H., Rosebrough, N.J., Farr, A.L. \& Randall, R.J. (1951) Protein measurement with the Folin phenol reagent. J. Biol. Chem., 193, 265-275.
Mahadik, S.P. \& Mukherjee, S. (1996) Free radical pathology, and antioxidant defense in schizophrenia: A review. Schizophr. Res., 19, 1-17.

McCord, J.M. \& Fridowich, I. (1969) Superoxide dismutase. An enzymatic function for erythrocuprein (hemocuprein). J. Biol. Chem., 244, 6049-6055.

McKee, J.R., Bodfish, J.W., Mahorney, S.L., Heeth, W.L. \& Ball, M.P. (2005) Metabolic effects associated with atypical antipsychotic treatment in the development disabled. $J$. Clin. Psychiatry, 66, 1161-1168.

Parikh, V., Khan, M.M. \& Mahadik, S.P. (2003) Differential effects of antipsychotics on expression of antioxidant enzymes and membrane lipid peroxidation in rat brain. $J$. Psychiatr. Res., 37, 43-51.

Savaş, H.A., Herken, H., Yürekli, M., Uz, E., Tutkun, H., Zoroğlu, S.S., Özen, M.E., Cengiz, B. \& Akyol, Ö. (2002) Possible Role of Nitric Oxide and Adrenomedullin in Bipolar Affective Disorder. Neuropsychobiology, 45, 57-61.

Sharpe, P.T. (1988) Methods of cell separation. In: Laboratory Techniques in Biochemistry and Molecular Biology, Vol. 18, edited by R.H. Burdon \& P.H. Knippenberg, Oxford: Elseiver, Amsterdam, NY, p. 272.

Sierra, H.M.R. \& Murphy, P.A. (1992) Supression of interleukin-1 action by phospholipase- $\mathrm{A}_{2}$ inhibitors in helper $\mathrm{T}$ lymphocytes. Peptide Res., 5, 258-261.

Uchiama, M. \& Mihara, M. (1978) Determination of malonaldehyde precursor in tissue by thiobarbituric acid test. Anal. Biochem., 86, 271-278.

Üstdal, K.M., Haspaylan, H., Saraymen, R. \& Kılıç, E. (2004) Investigation of erythrocyte SOD and CAT Levels of Patients with Bipolar Affective Disorder Treated with or Without Lithium. Erciyes Univ. J. Health Sci., 13, 16-20. (in Turkish)

Vanizor Kural, B., Örem, A., Cimsit, G.U., Yandi, Y.E. \& Calapoglu, M. (2003) Evaluation of the atherogenic tendency of lipids and lipoprotein content and their relationships with oxidant-antioxidant system in patients with psoriasis. Clin. Chim. Acta, 328, 71-82.

Yagi, K. (1994) Lipid peroxides and related radicals in clinical medicine. In: Free Radicals in Diagnostic Medicine, edited by D. Armstrong, Plenum Press, New York, pp. 1-15.

Yao, J.K., Reddy, R., McElhinny, L.G. \& van Kammen, D.P. (1998) Reduced status of plasma total antioxidant capacity in schizophrenia. Schizophr. Res., 32, 1-8. 